A N N A L E S Annales de Bretagne et des Pays de l'Ouest

\title{
La Vie de Jésus de Renan, la fabrique d'un best-seller
}

Hervé Martin

\section{(2) OpenEdition}

\section{Journals}

Édition électronique

URL : http://journals.openedition.org/abpo/3256

DOI : $10.4000 /$ abpo.3256

ISBN : 978-2-7535-5040-7

ISSN : 2108-6443

\section{Éditeur}

Presses universitaires de Rennes

Édition imprimée

Date de publication : 22 avril 2016

Pagination : 216-218

ISBN : 978-2-7535-5038-4

ISSN : 0399-0826

Référence électronique

Hervé Martin, "La Vie de Jésus de Renan, la fabrique d'un best-seller», Annales de Bretagne et des Pays de I'Ouest [En ligne], 123-1 | 2016, mis en ligne le 22 avril 2016, consulté le 23 septembre 2020. URL http://journals.openedition.org/abpo/3256 ; DOI : https://doi.org/10.4000/abpo.3256 
insistant sur la force symbolique des églises de la période concordataire, Stéphane Haugommard livre des réflexions qui constituent un jalon remarquable dans l'histoire des églises de la période concordataire et propose une base de réflexion fort utile à tous ceux qui s'intéressent aux enjeux patrimoniaux qu'elles soulèvent.

Samuel GICQUEL

RICHARD, Nathalie, La Vie de Jésus de Renan, la fabrique d'un best-seller, Rennes, PUR, coll. " Histoire ", 2015, 315 p.

Nathalie Richard, bien connue par deux ouvrages majeurs consacrés respectivement aux débuts de l'archéologie préhistorique en France et à Hippolyte Taine, a choisi cette fois de s'attaquer à la recherche des raisons profondes du succès de la Vie de Jésus d'Ernest Renan, publiée en juin 1863 par Michel Lévy. Plus qu'un succès, c'est un triomphe : au bout de six mois, le livre s'est déjà vendu à 70000 exemplaires. Un an plus tard, on approche des 150000 exemplaires. Ce brillant parcours s'est poursuivi jusqu'en 1947. Seul Victor Hugo a fait mieux avec Les Misérables! Comment expliquer cette foudroyante percée " médiatique " avant l'heure? Rappelons d'abord que l'ouvrage était attendu depuis que Renan avait vu suspendre son cours au Collège de France, le 26 février 1862, pour avoir quatre jours plus tôt, dans sa leçon inaugurale, qualifié Jésus d'" homme incomparable, si grand que je ne voudrais point contredire ceux qui l'appellent Dieu ". Il faut aussi tenir compte de l'habileté de l'éditeur Michel Lévy, très adroit dans la détection de jeunes auteurs talentueux et point alarmé, apparemment, par l'antisémitisme feutré de Renan. L'essor de la presse populaire bon marché a également contribué à la diffusion de l'ouvrage en relayant les polémiques entre les cléricaux et les anticléricaux.

Les mérites scientifiques du livre sont incontestables mais n'ont pas fait l'unanimité chez les contemporains : les catholiques les ont niés, les protestants les ont appréciés modérément et les libres penseurs les ont estimés insuffisants. Renan a adopté une perspective historiciste, définissant l'histoire comme la science des changements et lui assignant comme mission essentielle l'étude des langues et des religions, en insistant sur les origines des unes et des autres. Il pensait ainsi que les langues sémitiques permettaient de connaître "l'enfance de l'esprit humain ". Il concevait l'histoire comme une science du probable et du vraisemblable plutôt que du vrai, où s'exerçait " une force active et vivante ". Il estimait aussi devoir tenir compte de la race, de l'environnement, des contacts entre les aires culturelles et surtout de la liberté humaine. Dans son rapport aux sources, il en restait à une critique érudite bien tempérée, dont témoignait la confiance faite aux Évangiles considérés comme des "créations du sentiment populaire".

La Vie de Jésus a bénéficié de l'attrait exercé par le genre biographique, occasion rêvée pour le penseur breton de pratiquer la psychologie historique qu'il appelait de ses vœux. À ce niveau se posait la question cruciale des miracles attribués à Jésus. Sans y croire, Renan a choisi de se demander comment les contemporains avaient pu y prêter foi. Adoptant une via media, il voit dans les prodiges relatés par les évangélistes de pieuses fraudes, d'aimables légendes, en somme des faits réels transformés et embellis. Jésus lui-même n'y croyait sans doute pas, mais il aurait fait des concessions à ses disciples pour faire passer son message. Position d'autant plus facile à tenir que l'auteur garde le silence sur les noces de Cana et sur la multiplication des pains, se contentant de mentionner la résurrection de Lazare, attribuée à une supercherie familiale. Au-delà de la question lancinante des miracles, 
se pose le problème de l'apparition sur la scène historique du grand homme ou du prophète capable d'exprimer les aspirations profondes de ses contemporains. Ce fut le cas de Jésus, porteur d'un message radicalement nouveau adressé à l'ensemble de l'humanité, prônant une religion de la fraternité et de l'amour, sans temples ni prêtres, sous l'égide d'un Dieu aimant. D'aucuns n'ont pas manqué de rapprocher cette empathie pour un " homme incomparable " et ce souci affiché de " marcher dans les pas de Jésus » des élans mystiques du séminariste de Saint-Sulpice au début des années 1840.

Les mérites intrinsèques de l'ouvrage ne sont pas niables mais n'auraient pas suffi à assurer son succès. On touche là au cœur de la thèse soutenue par Nathalie Richard : la Vie de Jésus a grandement bénéficié de la polémique que sa parution a déclenchée. Les journaux libéraux n'ont pas manqué de saluer une étude débarrassée de toute croyance au surnaturel et apte à susciter "l'enthousiasme pour la beauté morale ", tout en regrettant que Renan reste trop timoré face à la religion et manque de rigueur dans sa démarche critique. Du côté bonapartiste, Sainte-Beuve a apprécié un ouvrage propre à satisfaire la masse croissante des sceptiques modérés. La presse monarchiste s'est déchaînée contre l'œuvre d'un apostat et contre un roman philosophique dépourvu de rigueur. Le Figaro, non content de dénoncer un phénomène de mode, a considéré Renan comme un impie désireux de s'attaquer au cœur du dogme chrétien et de ruiner la croyance à la divinité du Christ. Barbey d'Aurevilly a assimilé l'illustre universitaire à un Antéchrist au petit pied. Au cœur de cette agitation "médiatique ", l'Église catholique a déclenché contre le "renégat " et l'" hérétique " de Tréguier une virulente campagne qui, par son intensité, ses outrances et ses maladresses, a grandement contribué au succès de la Vie de Jésus. Les évêques ont dénoncé cet ouvrage pernicieux dans leurs mandements, les prédicateurs l'ont anathématisé dans leurs sermons, les journaux et les revues lui ont imputé " la mort de Jésus ", rien de moins! Louis Veuillot s'en est pris à l'" athéisme de saindoux " de l'auteur, alors que d'autres ont traité par le mépris un propos fondé sur des peut-être et des hypothèses hasardeuses. On a attaqué l'ancien séminariste, qualifié d'apostat, on a mis en cause ses compétences scientifiques, on lui a reproché d'avoir conçu un mauvais roman destiné à séduire le plus grand nombre en ramenant la religion au sentiment. Ce dernier argument n'était pas sans risque, car il conférait au livre incriminé l'attrait et la saveur du fruit défendu. Certains polémistes n'ont pas manqué de souligner que le Jésus de Renan était un anarchiste désireux de saper l'ordre social en exaltant les pauvres et en propageant la haine des possédants.

En proférant de telles outrances, les porte-parole du catholicisme français se sont tiré une balle dans le pied et ont fait la promotion du livre maudit. Cependant, Renan a contribué lui-même à la propagation de ses thèses en publiant en 1864 Jésus, version abrégée et bon marché de l'œuvre initiale, vendue à 80000 exemplaires en quelques mois. Ce faisant, le digne universitaire a adopté une posture d'écrivain populaire, caviardant les passages techniques et les notes, gommant les incertitudes et les hypothèses, se contentant en somme d'écrire une biographie du Messie, en restant très discret sur ses miracles et muet sur sa résurrection. En célébrant les qualités morales de Jésus et en prônant la religion pure, il a concurrencé la littérature de dévotion, très prospère dans les années 1860 ; en jouant de l'exotisme et en exaltant une Galilée idéale, il a usé de certains des attraits des romans à quatre sous. Il a donc travaillé sciemment à consolider un succès que l'on ne peut attribuer totalement à la propagande hostile de l'appareil catholique.

Dans un dernier chapitre, des plus passionnants, N. Richard analyse des lettres adressées à Renan par certains de ses lecteurs à partir de 1864. Ces missives procédaient d'artistes, de confrères, de gens du monde, mais aussi d'hommes et de 
femmes très modestes. On y trouve des louanges et des anathèmes, parfois versifiés, des demandes d'assistance financière ou autre, une offre de traduction en anglais. Les jugements négatifs reprennent les poncifs de la critique cléricale, faisant état de la douleur ressentie par les catholiques, appelant de leurs voux un autodafé du livre maudit ou menaçant son auteur du châtiment éternel. Les appréciations positives vantent une prise de distance opportune avec des cadres religieux contraignants et une propédeutique salutaire à la liberté de penser.

Dans une magistrale conclusion, $\mathrm{N}$. Richard souligne le côté éphémère de la gloire de Renan. Il a été lu par d'innombrables lecteurs et a été l'objet de multiples lectures, il a été traduit en plusieurs langues, considéré comme un grand homme par la Troisième République et vénéré comme un maître à penser entre 1860 et 1880 . Toutefois, passée cette dernière date, son aura a faibli. Son projet de bâtir une science du développement de l'esprit humain en accordant une place primordiale aux langues et aux mythes n'a pas résisté à l'essor de disciplines séparées. Les historiens de l'école méthodique ne se sont pas contentés de sa critique bien tempérée des sources et n'ont retenu de lui que sa sympathie envers les hommes du passé. Les philosophes ont rejeté son éclectisme et son impressionnisme, ainsi que ses penchants littéraires et artistiques. En prônant l'étude des faits sociaux et non celle des faits moraux, Durkheim a récusé une histoire des religions dépourvue de bases scientifiques solides.

Par ce livre de haute volée, N. Richard apporte une contribution de poids à l'histoire culturelle du XIX ${ }^{\mathrm{e}}$ siècle. Elle devrait rencontrer un écho particulier en Bretagne, cette province ayant vu naître quatre penseurs et écrivains de premier plan qui se sont attaqués au cœur du problème chrétien. Si Chateaubriand a entrepris de glorifier le christianisme au lendemain de la tourmente révolutionnaire en exaltant la beauté de ses œuvres, Abélard ne s'était pas privé, dès le xiI ${ }^{\mathrm{e}}$ siècle, dans le Sic et Non, de recenser des affirmations contradictoires dans les écrits des Pères de l'Église. En 1846, dans son commentaire des Évangiles, Félicité de Lamennais a qualifié Jésus de "philosophe inspiré " après avoir soutenu dans les Discussions critiques de 1841 l'opinion suivante : "Il y a des miracles quand on y croit; ils disparaissent quand on n'y croit plus ". Fermant la marche, Renan a poussé le principe scolastique de la foi en quête d'intelligence (fides quaerens intellectum) jusqu'à sa limite extrême, jusqu'à ce point où la raison remet la foi en cause, au lieu de lui servir d'arc-boutant. Le franchissement de cette frontière portait inévitablement un coup fatal à la croyance aux miracles et, dans un second temps, au dogme la divinité de Jésus.

Hervé MARTIN

DuPLEsSIX, Angélina [collectés par], Chansons et contes de Haute-Bretagne, Une transmission orale au coeur de la bourgeoisie rennais, $X I X^{e}-X X^{e}$ siècles, Rennes, Dastum/ La Bouèze/PUR, coll. " Patrimoine oral de Bretagne ", avant-propos et présentation de Vincent Morel, 2015, 280 p.

Voilà un ouvrage peu banal et dont, disons-le d'entrée, on ne peut que féliciter chaudement les trois co-éditeurs. On sait à quel point la collecte des contes, légendes et chansons " populaires " $\operatorname{aux~XIX}{ }^{\mathrm{e}}$ et $\mathrm{XX}^{\mathrm{e}}$ siècles s'est identifiée à un seul type de sources, celle des hommes et femmes du peuple, ruraux dans une écrasante majorité, teilleurs et tisserands, tailleurs et couturières, cultivateurs et mendiants, colporteurs et rhapsodes foraines. Même quand un intermédiaire " bourgeois " ou " lettré " a transcrit les récits et chansons, ce qui est assez fréquent, la source primi- 